\title{
As duas vias do princípio das vantagens comparativas de David Ricardo e o padrão-ouro: um ensaio crítico
}

The two ways of Ricardo's principle of comparative advantages and the gold standard: a critical essay. This article critically resumes Ricardo's principle of comparative advantages pointing out internal coherence problems that have been neglected by the specialized literature. First, long-lasting disequilibria observed in the balance of trade seem incompatible with the idea that these disequilibria are caused by technical advances that change relative prices. Second, comparative advantages do not seem to work in an economy with a universally accepted commodity-money. Finally, the contradiction between the gold standard mechanisms, ruled by Smith's "Law of Reflux", and the quantitative theory of money, which is a necessary condition for the "second way" of the theory of comparative advantages.

Key-words: International trade theory; Ricardian international trade theory; comparative advantages.

JEL Classification: F10.

\section{INTRODUÇÃO}

Entre todas as idéias de David Ricardo, certamente que uma das de maior sucesso seja a teoria das vantagens comparativas, que, segundo Samuelson (2001:1204) continua sendo "um dos mais úteis e estimados princípios da economia política". ${ }^{1}$ De fato, desde a publicação dos Princípios de Economia Política e Tributação que a teoria do comércio internacional tem sido inteiramente do-

\footnotetext{
*Professor da Faculdade de Ciências Econômicas da Universidade Federal de Minas Gerais e da Faculdade de Estudos Administrativos de Minas Gerais. E-mail: claudio.gontijo@fead.br. Submetido: dezembro 2005; aceito: março 2006.

${ }^{1}$ A questão da paternidade do princípio das vantagens comparativas tem sido objeto de controvérsia entre os economistas. Para Chipman (1965: 482), ambos "Torrens e Ricardo contribuíram de forma
} 
minada por esse "princípio", incorporado não apenas à abordagem de oferta e demanda (Chipman, 1966b), mas também à teoria neo-ricardiana (ou sraffiana) do comércio internacional, que apontou a inaplicabilidade do modelo neoclássico numa economia com produtos heterogêneos (Metcalfe e Steedman, 1972 e 1973; Evans, 1989a). Mesmo a "nova economia internacional" (Krugman, 1984 e 1986; Brander e Spencer, 1985; Eaton e Grossman, 1986; Grossman e Horn, 1988; Grossman e Helpman, 1991), que recorre às economias de escala e à concorrência imperfeita para explicar o comércio inter-indústria, não contesta o princípio, que continuaria a explicar, no pior dos casos, o comércio Norte-Sul.

Apesar disso, a teoria do comércio internacional de Ricardo continua sendo abordada de forma superficial, desconectada da sua teoria dos preços "naturais" e da sua teoria da moeda-mercadoria. Em geral, os livros-texto de economia internacional (veja-se, por exemplo, Carbaugh (2002: 31-36); Gonçalves, Braumann, Canuto e Prado (1998: 14-16); Williamson (1993: 20-25); Caves, Frankel e Jones (1990: 8-9); Ethier (1988); Krugman e Obstfeld (1988: 13-44); e FfrenchDavis (1978: 26-28) apresentam uma versão sumária e neoclassizada a respeito, em franco desacordo com o que se depreende de uma análise mais demorada das obras de Ricardo. ${ }^{2}$ A explicação desse descuido radica, em grande parte, na perspectiva adotada, que concebe a teoria ricardiana como precursora do modelo de Heckscher-Ohlin, que emergiria com a adoção das hipóteses de coeficientes variáveis e de múltiplos fatores de produção.

Também não se pode afirmar que os modelos de "Ricardo-Viner" (ou modelo de "fatores específicos"; veja-se Krugman e Obstfeld (1988: 45-78), de Findlay (1974); ver também Jones (1971: 3-21) e de Dornbush, Fischer e Samuelson (1977), retratam o pensamento de Ricardo. Enquanto o primeiro assume que cada setor usa um fator de produção específico e um fator "móvel” (trabalho), comum a todos os outros, ${ }^{3}$ o segundo divide a economia nos setores de produção de "grãos", que são produzidos usando-se terra e trabalho sob rendimentos decrescentes, e de manufaturados, produzidos somente com o trabalho em condições de retornos constantes. Já o modelo de Dornbush, Fischer e Samuelson integra os lados real e monetário numa economia com um contínuo de bens.

Finalmente, tampouco têm os autores neo-ricardianos se preocupado em analisar a teoria das vantagens comparativas no contexto da obra de Ricardo. Embora se encontre uma exposição da teoria ricardiana em Metcalfe (1993) e Evans (1989a), as principais contribuições dos autores dessa abordagem têm se

essencial para o desenvolvimento da lei das vantagens comparativas; e o crédito pela principal descoberta deve ir para Torrens". Thweat (1976) afirma que as origens do princípio remontam a James Mill, enquanto Gomes (1987: 144) se trata de uma descoberta múltipla.

2 Conforme questiona Maneschi (1992: 422), a questão radical em saber se o modelo "ricardiano" desses livros-texto "é representativo do modelo de comércio implícito nos Princípios de Ricardo e de seus outros textos".

${ }^{3}$ Segundo Maneschi (1992: 422-423), não há nada nesse modelo que autorize sua filiação a Viner. 
restringido a demonstrar, por um lado, que a teoria de Ricardo se aplica numa economia com vários fatores de produção e coeficientes variáveis e, por outro lado, que o modelo de Heckscher-Ohlin é inconsistente quando se consideram bens de capital produzidos.

Este ensaio procura preencher essa lacuna, re-examinando o princípio das vantagens comparativas no conjunto das obras de Ricardo, tomando-se em conta, em particular, as suas formulações em termos de teoria de preços, de teoria monetária e dos mecanismos de ajuste do balanço de pagamento.

A discussão desdobra-se em sete seções além desta introdução. As limitações da defesa do livre comércio por Adam Smith, baseada na noção de vantagens absolutas, assim como a teoria ricardiana das vantagens comparativas, são apresentadas na seção 2 . Na seção 3, discutem-se os mecanismos de ajuste dos desequilíbrios do balanço de pagamentos. As contradições do princípio das vantagens comparativas são examinadas na seção 4. A discussão do que denominamos por "segunda via" da teoria das vantagens comparativas está nas seções 5 e 6 . A seção 7 contém as conclusões.

\section{A TEORIA DAS VANTAGENS COMPARATIVAS DE RICARDO}

Apesar de ter influenciado várias publicações sobre economia internacional que apareceram depois da publicação de A Riqueza das Nações, ${ }^{4}$ ao observador moderno parece claro que a defesa smithiana do livre comércio - baseada na teoria das vantagens absolutas - era claramente insuficiente, tendo em vista as necessidades da ascendente burguesia industrial inglesa, em luta não apenas contra o intervencionismo estatal e as práticas mercantilistas que ainda prevaleciam em fins do século XVIII e princípios do século XIX, mas também para fortalecer a sua posição no cenário internacional.

Para começar, a teoria do comércio internacional de Adam Smith mostrouse vulnerável ao "argumento da indústria infante", que estabelece que, mesmo aceitando-se a tese de que o livre comércio traz ganhos aos parceiros comerciais envolvidos, ainda assim seria possível afirmar que justificar a proteção de dado setor pelo período de tempo necessário para que ele adquirisse a capacidade de competir com sucesso nos mercados interno e externo. ${ }^{5}$

Em segundo lugar, na hipótese de determinado país possuir vantagens absolutas em setores onde a demanda mundial for pequena ou até nem mesmo pos-

\footnotetext{
${ }^{4}$ É o caso das Considerações sobre os Efeitos das Tarifas Protecionistas, obra que apareceu em 1783, e dos Novos e Velhos Princípios de Comércio Comparados, de Benjamin Vaughan, de 1788.

${ }^{5}$ Segundo Irwin (1998: 116), o argumento da indústria infante é a mais antiga e robusta justificativa em prol do protecionismo. Argumentos nele baseados podem ser encontrados em vários autores, como Andrew Yarranton (1677: 62), William Wood (1718: 224-225); Teodore Janssen (1713: 9), Arthur Dobbs (1729: 65); Francis Hutcheson (1753: 308); Josiah Tucker (1758: 50-51) e, finalmente, em James Steuart (1767: 262-263).
} 
suir quaisquer vantagens absolutas, a teoria smithana deixava implícita a conclusão de que o país seria arruinado pelo livre comércio, sendo eventualmente excluído da economia internacional. Além disso, no contexto de vantagens absolutas, países não produtores de ouro que apresentassem déficits permanentes na balança comercial, seriam obrigados a restringir o seu ritmo de crescimento econômico ou mesmo os níveis de renda e de emprego. Finalmente, a crença smithiana em economias crescentes de escala - explicitada no famoso exemplo da fábrica de alfinete -, poderia ser facilmente transformada em argumento em favor da reserva e conquista de mercados, ou seja, do protecionismo, colonialismo e imperialismo.

O grande mérito de Ricardo foi o de apresentar uma teoria do comércio internacional - baseada no "princípio das vantagens comparativas" — que aparentemente solucionava os problemas apresentados pela abordagem smithiana, fornecendo um mecanismo automático de ajustamento do balanço de pagamentos e uma demonstração de que todos os países, independente da estrutura de custos de sua economia, ganhariam com o livre comércio.

Para esclarecer esse "princípio", Ricardo (1817, Cap. VII: 104-105) constrói um exemplo com apenas dois países - Portugal e Inglaterra - e somente dois bens - vinho e tecidos (Tabela 1), recorrendo à teoria do valor-trabalho, segundo a qual a razão de troca entre mercadorias é proporcional ao tempo de trabalho social gasto na produção delas. A explicação de não ter se utilizado a sua teoria dos "preços naturais" talvez resida na crença de que a produtividade do trabalho é o principal determinante dos preços de equilíbrio (Ricardo, 1817, Cap. I: 56). Outra alternativa seria tornar claro que até os países sem qualquer vantagem absoluta se beneficiariam do comércio internacional.

Tabela 1: Quantidade de trabalho gasto na produção em homens-ano

\begin{tabular}{lcc}
\hline Discriminação & Portugal & Inglaterra \\
\hline Vinho (tonel) & 80 & 120 \\
\hline Tecidos (peça) & 90 & 100 \\
\hline Preço vinho/tecido & $80 / 90=0,888 \ldots$ & $120 / 100=1,20$ \\
\hline Preço tecido/vinho & $90 / 80=1,125$ & $100 / 120=0,83333 \ldots$ \\
\hline
\end{tabular}

Suponha que, conforme informa a Tabela 1 , o tonel de vinho valha 80/90 = 0,888 peças de tecido em Portugal e $120 / 100=1,20$ peças de tecido na Inglaterra; ou seja, uma peça de tecido valha $90 / 80=1,125$ tonéis de vinho em Portugal e 100/120 = 0,8333 na Inglaterra. Assumindo, então, que esses dois países assinem um tratado de livre-comércio e que - apenas para efeitos de simplificação — os custos de transporte sejam desprezíveis, um comerciante poderia transportar 1.000 peças de tecido da Inglaterra para Portugal, onde poderia trocá-las por $1.000 \times 1,125=1.125$ tonéis de vinho. Transportando, então, o vinho assim obtido para a Inglaterra, poderia trocá-lo novamente por tecidos, obtendo $1.125 \mathrm{x}$ 
$1,20=1.350$ peças de tecido. A operação, portanto, daria um ganho de 350 peças de tecido (ou $35 \%$ ) toda vez que fosse realizada. De forma simétrica, um comerciante poderia obter 1.000 tonéis de vinho em Portugal, trocá-los por 1.000 x $1,20=1.200$ peças de tecido na Inglaterra, transportá-los para Portugal e trocá-los por $1.200 \times 1,125=1.350$ tonéis de vinho, o que produziria um ganho de 350 tonéis por operação, isto é, de $35 \%$.

Conforme conclui Ricardo (1817, Cap. VII: 104-105):

"em Portugal, a produção de vinho pode requerer somente o trabalho de 80 homens por ano, enquanto a fabricação de tecido necessita do emprego de 90 homens durante o mesmo tempo. Será, portanto, vantajoso para Portugal exportar vinho em troca de tecidos. Essa troca poderia ocorrer mesmo que a mercadoria importada pelos portugueses fosse produzida em seu país com menor quantidade de trabalho que na Inglaterra. Embora Portugal pudesse fabricar tecidos com o trabalho de 90 homens, deveria ainda assim importá-los de um país onde fosse necessário o emprego de 100 homens, porque lhe seria mais vantajoso aplicar seu capital na produção de vinho, pelo qual poderia obter mais tecido na Inglaterra do que se desviasse parte de seu capital do cultivo da uva para a manufatura daquele produto."

Apesar do raciocínio acima ter sido construído com base na comparação entre as quantidades de trabalho despendido na produção de cada uma das mercadorias, ele é perfeitamente válido se, em lugar do trabalho, se utilizar os preços de equilíbrio ("preços naturais", na terminologia ricardiana). Ou seja, ao contrário da teoria das vantagens absolutas, que requer a comparabilidade dos valores internacionais, a teoria das vantagens relativas se aplica conhecendo-se apenas os preços relativos. Assim, poder-se-ia supor que, no caso do Exemplo 1, 80/90 e 120/100 representassem os preços de equilíbrio de um tonel de vinho em relação ao preço de equilíbrio de uma peça de tecidos em Portugal e na Inglaterra, respectivamente. Mais do que isso, como se assume que o dinheiro é uma mercadoria (ouro), se supuséssemos, por exemplo, que o preço de um tonel de vinho fosse de 45 moedas de ouro de uma libra em Portugal e de 66 moedas na Inglaterra, ter-se-ia que o preço de uma peça de tecido no primeiro país seria de $£ 50,625$ e de $£ 55,00$ no segundo. Parece óbvio que essa alteração na unidade de medida não afetaria em nada o raciocínio anterior, pois as relações de troca entre os dois produtos continuariam as mesmas.

É claro que, conforme salienta Ricardo (1817, Cap. VII: 105), “os tecidos não serão importados por Portugal a menos que lá possam ser vendidos por mais ouro do que custaria no país do qual foram importados; e o vinho não entraria na Inglaterra a menos que pudesse ser vendido por mais do que custa em Portugal", o que significa que as relações de troca entre vinho e tecidos nos dois países teriam de ser diferentes e se situar entre $£ 45 / £ 50,625$ e $£ 66 / £ 55$ para que houvesse comércio entre os dois países. Para atrair compradores ingleses, os comer- 
ciantes teriam, assim, de vender o vinho português a um preço ligeiramente abaixo do preço do vinho inglês, ou seja, poderiam oferecer o produto importado a $£ 61$, em lugar de $£ 66$, o que levaria à progressiva conquista do mercado inglês de vinho pelo produto português. Nesse caso, 1.000 tonéis de vinho trazidos de Portugal seriam trocados por $£ 61 / £ 55=1.109$ peças de tecidos na Inglaterra, ou seja, o equivalente a 1.109 × 1,125 = 1.247,6 tonéis de vinho em Portugal, o que implicaria num ganho de 247,6 tonéis. Da mesma maneira, para conquistar o mercado português para os tecidos ingleses, os comerciantes necessitariam oferecer o produto importado da Inglaterra por um preço mais baixo do que o concorrente local. Poderiam, portanto, oferecê-lo a $£ 49$ por unidade. Nesse caso, com as 1.109 peças de tecidos conseguidas na Inglaterra em troca de 1.000 tonéis de vinho português, seriam obtidos $109 \times £ 49 / £ 45=1.118,7$ tonéis, o que ainda representa um ganho de 118,7 tonéis.

O exemplo acima ilustra como, segundo a teoria das vantagens comparativas de Ricardo, o livre comércio, induzindo os parceiros comerciais a se especializarem naqueles produtos que são comparativamente mais eficientes, é benéfico para todos os países, mesmo para aqueles que são menos eficientes, em termos absolutos, na produção de todos os bens e serviços. Obviamente, a teoria é dita de vantagens comparativas porque um país pode ser menos eficiente do que outro na produção de todos os bens e serviços e, ainda assim, a especialização produtiva induzida pelo comércio exterior seria vantajosa para ele.

\section{VANTAGENS COMPARATIVAS E OS DESEQUILÍBRIOS DA BALANÇA COMERCIAL}

$\mathrm{Na}$ explicação ricardiana das vantagens comparativas fica claro que o processo do comércio internacional envolve a troca de produtos, pois é através desse intercâmbio que os comerciantes têm ganhos. Nesse contexto, fica difícil dar conta da existência de desequilíbrios persistentes da balança comercial, o que aparentemente pressupõe a independência dos atos de exportação e importação. Não é sem motivo, aliás, que Ricardo explica o desequilíbrio na balança de comércio exterior como um fenômeno associado à mudança das pautas de exportação/importação decorrente de avanços tecnológicos que alteram os preços relativos, modificando, por via de conseqüência, as vantagens comparativas.

Com efeito, Ricardo (1817, Cap. VII: 106-108) supõe que, uma vez estabelecido o comércio entre os dois países, a Inglaterra descubra um novo processo de produzir vinho, de forma que o preço do vinho produzido domesticamente caia para $£ 45$, em lugar de $£ 50$. Como conseqüência, "o tecido continuaria a ser exportado durante algum tempo, já que seu preço permaneceria maior em Portugal" do que na Inglaterra, mas, "em troca dele seria dado dinheiro, em vez de vinho", uma vez que Portugal teria deixado de exportar esse produto, mas continuaria importando tecidos. O conseqüente déficit na balança comercial somente seria sustentável no longo prazo caso Portugal produzisse ouro, tivesse superávit de dimensões semelhantes com outro país, ou atraísse capital externo (de 
empréstimo ou de risco), hipóteses que Ricardo não analisa, até porque, conforme salienta (Ricardo, 1817, Cap. VII: 104-105), não havia, à época, movimentos de capital entre países.

Para solucionar o problema, Ricardo recorre então à teoria do ajuste automático do balanço de pagamentos desenvolvida por Hume (1747: 330-345), que conecta o resultado da balança comercial à quantidade de moeda e ao nível de preços. Para explicar os mecanismos de conexão, Hume supõe que quatro quintos do dinheiro da Grã-Bretanha tivesse desaparecido durante a noite, passando, em seguida, a examinar as conseqüências do fato. Segundo ele, os salários e os preços das mercadorias britânicas cairiam na mesma proporção, tornando-as mais baratas do que as mercadorias estrangeiras nos mercados externos. Como resultado, haveria um forte acréscimo nas exportações, que seriam pagas em dinheiro, aumentando sua quantidade no país, o que faria com que os preços se elevassem. O processo continuaria até que o "nível do dinheiro" no Reino Unido fosse o mesmo do que nos países vizinhos. $\mathrm{O}$ inverso ocorreria se a quantidade de dinheiro fosse multiplicada por cinco durante a noite: os salários e os preços subiriam proporcionalmente no país, causando desequilíbrio na balança comercial, com o dinheiro saindo da Grã-Bretanha para o exterior. À medida que isso ocorresse, haveria a queda do nível de preços até se restabelecer o equilíbrio anterior. Um mecanismo adicional, ainda que menos importante, seria as flutuações da taxa de câmbio dentro dos limites dos "pontos de ouro". Se a balança comercial britânica fosse deficitária, haveria a valorização do câmbio, favorecendo as exportações de produtos ingleses, ocorrendo o inverso no caso de um superávit. ${ }^{6}$

Aplicando-se o mecanismo ao exemplo em consideração, tem-se que, se, conforme assinalado, o preço do vinho inglês caísse para $£ 45$ como resultado de uma invenção tecnológica, isso não afetaria, no início, a importação de tecidos ingleses, que prosseguiria. $\mathrm{O}$ importador português, portanto, adquiriria, como antes, letras de câmbio cotadas em libras esterlinas com dinheiro português. David Ricardo (1817, Cap. VII: 106-107) pondera, contudo, que

Se, no entanto, os preços do vinho fossem tais que não se pudesse exportá-lo para a Inglaterra, o importador de tecidos teria, da mesma forma, que comprar uma letra. Mas o preço desse título seria maior, pois o seu vendedor saberia não existir no mercado um contra-título por meio do qual se pudesse liquidar a transação entre os dois países. Portanto, o dinheiro em ouro ou prata que recebesse em troca da letra, deveria ser enviado a seu correspondente na Inglaterra, para permitir-lhe pagar o saque autorizado contra ele. Assim, deveria acrescentar ao preço da letra todas as despesas em que devesse incorrer, juntamente com seu devido lucro habitual. Se o prêmio de uma letra na Inglaterra fosse igual ao lucro da importação de tecidos, esta certamente cessaria. Mas, se o prêmio sobre a letra fosse de apenas $2 \%$, e se, para a liquidação de

\footnotetext{
${ }^{6}$ Veja-se também Viner (1937: 292-293) e Angell (1925: 24-27).
} 
uma dívida de 100 libras na Inglaterra, bastasse pagar 102 libras em Portugal, enquanto o tecido que custasse 45 libras pudesse ser vendido por 50 libras, o tecido seria importado, as letras seriam compradas e o dinheiro seria exportado, até que a redução do dinheiro em Portugal, e sua acumulação na Inglaterra, produzissem tal situação de preços que já não fosse vantajoso continuar as transações."

Em outras palavras, o déficit na balança comercial de Portugal reduziria a quantidade de dinheiro em circulação nesse país, enquanto o superávit a aumentaria na Inglaterra, fazendo com que o nível de preços caísse no primeiro e se elevasse no segundo. Como afirma Ricardo (1817, Cap. VII: 107):

“a redução do dinheiro num país e seu aumento em outro não influem apenas no preço de uma mercadoria, mas no preço de todas. Assim, os preços do vinho e dos tecidos aumentarão na Inglaterra e ambos se tornarão mais baratos em Portugal. Se o preço dos tecidos fosse 45 libras num país e 50 libras em outro, provavelmente diminuiria para 49 ou 48 em Portugal, e aumentaria para 45 ou 47 libras na Inglaterra, não permitindo um lucro suficientemente alto, após o pagamento do prêmio da letra, para estimular o negociante a importar aquela mercadoria."

Diante dessas palavras, poder-se-ia pensar que, tendo cessado as exportações de vinho, o término das importações de tecidos significaria o fim do comércio entre os dois países. Na verdade, a intenção de Ricardo é demonstrar que, dada uma situação de especialização produtiva, induzida pelo livre comércio, a introdução de uma inovação técnica poderia inverter as vantagens comparativas, o que causaria, no primeiro momento, um desequilíbrio na balança comercial, que seria eliminado pela elevação/queda do nível de preços. O conseqüente término do comércio, contudo, seria de curta duração, pois os comerciantes dos dois países não demorariam muito em descobrir as vantagens de trocar produtos com base nos novos preços relativos, tendo início, novamente, o processo de especialização produtiva e de intercâmbio comercial entre os países.

\section{MOEDA-MERCADORIA E A "SEGUNDA VIA" DO PRINCÍPIO DAS VANTAGENS COMPARATIVAS}

Não é difícil perceber, a partir da análise da explicação ricardiana dos desequilíbrios da balança comercial (seção 4), expressa no Capítulo VII dos Princípios, seu caráter insatisfatório, que pressupõe, para começar, que esses desequilíbrios fossem de natureza transitória, originados por mudanças tecnológicas que revertem a estrutura de preços relativos, alterando, por conseguinte, a ordem das vantagens comparativas. Além disso, o processo seria caracterizado pela redução temporária dos níveis de comércio, assim como pela modificação das pautas de exportação/importação dos países envolvidos. Tudo isso contrasta vivamente com 
os "fatos estilizados" do comércio exterior, bem conhecidos antes mesmo de Ricardo, marcado pela persistência, durante longos períodos, por desequilíbrios nas balanças comerciais e permanência dos volumes e fluxos de comércio no tempo.

Uma segunda dificuldade associada ao princípio das vantagens comparativas de Ricardo consiste em que, como não é difícil de se demonstrar, o mesmo fato aparentemente não funciona num contexto em que o dinheiro mundial é uma mercadoria, como no caso do padrão-ouro. Para entender por que, tome-se o exemplo anterior, assumindo que a quantidade de trabalho gasto na produção de uma moeda de uma libra de ouro fosse de 80/45 (= 1,777...) homem-ano em Portugal e de $120 / 66$ ( = 1,818181...) homem-ano na Inglaterra. Admitindo, apenas para não complicar ainda mais a questão, que as razões de troca fossem proporcionais à quantidade de trabalho gasto na produção dos bens e serviços, poder-se-ia montar a tabela a seguir, com o valor desses produtos em libras de ouro.

Tabela 2: preço de vinho e tecidos em $£$ de ouro

\begin{tabular}{lcc}
\hline Discriminação & Portugal & Inglaterra \\
\hline Vinho (tonel) & 45,000 & 66,00 \\
\hline Tecidos (peça) & 50,625 & 55,00 \\
\hline
\end{tabular}

Conforme se pode verificar, os preços relativos são exatamente os mesmos considerados na Tabela 1, de forma que seria de se esperar que, segundo a teoria das vantagens comparativas, Portugal se especializasse na produção de vinho, trocando esse produto por tecidos provindos da Inglaterra, que também se especializaria na produção desses últimos. Suponha, então, que, seguindo a seqüência do exemplo discutido na seção 2, um comerciante comprasse 1.000 barris de vinho em Portugal para vender na Inglaterra. Como o preço do barril de vinho é de $£ 45$ em Portugal, o comerciante gastaria $£ 45.000$ na compra, obtendo $£ 66.000 \mathrm{com}$ a venda dos mesmos barris na Inglaterra. Tendo vendido o vinho na Inglaterra, o mesmo comerciante, contudo, não compraria tecidos nesse país, pois, caso o fizesse, obteria somente $£ 66.000 / £ 55=1.200$ peças, quando poderia obter $£ 66.000 / £ 50,625$ $=1.303,7$ peças se efetuasse a compra em Portugal. Vendendo essas peças na Inglaterra, obteria $£ 71.703,7$, o que significa um rendimento, ao fim e ao cabo, de $59,3 \%$ (= $100 * £ 71.703$, $7 / £ 45.000-100)$, em lugar dos $35 \%$ que seriam obtidos caso seguisse o prescrito pela teoria das vantagens comparativas. Em outras palavras, seria lucrativo comprar vinho e tecidos em Portugal e exportá-los para a Inglaterra, de forma que, em quaisquer circunstâncias, a compra de tecidos na Inglaterra, ainda que fosse para trocá-los por vinho inglês para ser vendido na Inglaterra para novamente se obter tecido inglês, daria prejuízo.

Conclui-se, assim, que o princípio das vantagens comparativas, tal como exposto no Capítulo VII dos Princípios, parece não funcionar num contexto em que, como no padrão-ouro, o dinheiro é uma mercadoria aceita universalmente, de forma que, quem o possuir, pode comprar o que quiser onde quiser, sendo, 
portanto, de se esperar que compre onde for mais barato em termos absolutos, ou seja, onde os produtos cotados em ouro custem menos.

Contudo, com base na análise ricardiana dos desequilíbrios na balança comercial apresentada na seção 4, poder-se-ia argumentar que, no exemplo acima, caso os comerciantes comprassem tudo em Portugal para vender na Inglaterra, o déficit da balança comercial britânica resultaria na queda dos preços na Inglaterra, enquanto o superávit na balança de Portugal provocaria a elevação do nível de preços nesse país. Caso, por exemplo, houvesse uma elevação de $5 \%$ do nível de preços em Portugal e uma queda de $5 \%$ do nível de preços no Reino Unido, o preço da peça de tecidos nesse país seria de $£ 52,25$; abaixo, portanto, do preço do mesmo produto em Portugal, que seria de $£ 53,16$. Como resultado, haveria uma rápida redução das importações de tecidos portugueses pela Inglaterra, que passaria a exportar o produto. O processo prosseguiria, então, até que houvesse o equilíbrio da balança comercial, com os dois países trocando os produtos em que tivessem vantagens relativas.

Em resumo, a teoria do comércio internacional de Ricardo poderia ser reinterpretada como resultante da sua teoria do ajustamento do balanço de pagamentos que pressupõe a teoria quantitativa da moeda, uma vez que o nível de preços varia com a quantidade de moeda em circulação. Observe-se que, nesse caso, os desequilíbrios da balança comercial deixam de ser fenômenos resultantes de avanços tecnológicos que modificam a estrutura de preços relativos, como quer Ricardo, mas se transformariam em componentes do próprio mecanismo através do qual operam as vantagens comparativas. Embora represente um desvio em relação ao pensamento ricardiano expresso no Capítulo VII dos Princípios, nele se inspira, dando, pelo menos aparentemente, a consistência desejada ao princípio das vantagens comparativas.

\section{RICARDO E A TEORIA QUANTITATIVA DA MOEDA}

O desenvolvimento da teoria monetária ricardiana deu-se no decorrer da chamada "controvérsia bullionista", que se originou como resultado das tentativas de explicar o processo inflacionário subseqüente à suspensão da conversibilidade das notas do Banco da Inglaterra em ouro, em 1797. Os "bullionistas" explicavam a inflação como conseqüência das emissões de papel-moeda inconversível pelo Banco da Inglaterra, enquanto os “anti-bullionistas” minimizavam ou rejeitavam integralmente o papel da expansão monetária no processo inflacionário, atribuindo-o primariamente aos distúrbios causados nas correntes de comércio pela guerra com a França e às despesas do governo inglês por conta do conflito armado, que provocaram forte elevação da taxa de câmbio.

A argumentação de Ricardo, de natureza "bullionista”, pode ser encontrada em três cartas endereçadas ao periódico inglês Morning Chronicle, publicadas entre agosto e novembro de 1809, nos opúsculos High Price of Bullion e Reply to Mr.Bonsanquet's Practical Observations on the Report of the Bullion Comit- 
tee (1811), assim como no trabalho Proposals for an Economic and Secure Currency (1816) e nos capítulos correspondentes dos Princípios de Economia Política e Tributação (1817).

Ao ingressar na controvérsia, Ricardo seguiu de perto a teoria monetária de Adam Smith, considerando o dinheiro, em primeiro lugar, como uma mercadoria (ouro e prata) que, assim, deve distinguir-se do papel-moeda (notas bancárias). Como conseqüência, o ouro e a prata, como outras mercadorias, "têm um valor intrínseco, que não é arbitrário, mas depende da sua escassez, da quantidade de trabalho despendido na procura deles e do valor do capital empregado nas minas que os produzem" (Ricardo, 1811: 3). Essa concepção, juntamente com a noção smithiana de "preços naturais", significa que, no longo prazo, os preços monetários são determinados pelos custos de produção das mercadorias em relação ao custo de produção da moeda-padrão de ouro ou prata. Segue-se, pois, que, também no longo prazo, a quantidade de meios de circulação ajusta-se às necessidades da circulação mercantil.

O mecanismo de ajuste da oferta à demanda por dinheiro é a "lei do preço único", que estabelece que, em equilíbrio, "os metais preciosos empregados na circulação das mercadorias do mundo" preservam "o mesmo valor em todo lugar" (Ricardo, 1811: 3). Na eventualidade de um excesso de demanda por meios de circulação, os preços monetários caem abaixo dos preços internacionais, provocando um aumento das exportações. As conseqüentes entradas de ouro resultam na expansão da oferta de moeda em circulação, equilibrando oferta e demanda por moeda. Inversamente, caso haja um excesso de oferta, os preços internos se elevam acima dos preços internacionais causando a saída de ouro, que reduz a oferta interna de meios de circulação. Mesmo a descoberta de uma nova mina de ouro não causaria nenhum excesso de moeda em relação à quantidade requerida para a preservação do nível de preços, pois o excesso de ouro em circulação seria exportado até que se re-estabelecesse o equilíbrio (Ricardo, 1811: 4-5).

Esse mecanismo não é alterado pela introdução do "papel-moeda", desde que se assegure a conversibilidade:

"se, em lugar da descoberta de uma mina em dado país, fosse estabelecido um banco, como o Banco da Inglaterra, com o poder de emitir notas como meio de circulação; depois de um grande montante de notas ter sido emitido, quer através de empréstimos aos mercadores, quer através de empréstimos ao governo, dessa forma adicionando consideravelmente à soma do meio circulante, seguir-se-iam os mesmos efeitos da descoberta de uma mina. O equilíbrio entre essa nação e as outras seria restaurado pela exportação de parte da moeda metálica" (Ricardo, 1811: 5).

Esse mecanismo está intimamente conectado à "lei do refluxo" de Adam Smith, uma vez que os bancos "nunca poderiam emitir mais notas do que o valor da moeda metálica que teria circulado se não houvesse qualquer banco". De fato, "se esses tentassem exceder esse montante, o excesso retornaria imediata- 
mente para ser convertido em espécie; porque nossa moeda, estando dessa forma com valor diminuído, poderia ser vantajosamente exportada e não poderia ser retida em nossa circulação" (Ricardo, 1811: 7).

Outra idéia smithiana adotada por Ricardo é a de que, no longo prazo, a taxa de câmbio depende do peso em metal precioso nela contido, de forma que, considerando-se diversos países, "uma comparação do peso em metal fino das suas moedas capacita-nos a determinar as suas taxas de câmbio ao par" (Ricardo, 1811: 18). A taxa de câmbio de mercado pode flutuar em torno da posição de equilíbrio, definida dessa forma, estando os limites dessa flutuação definidas pelos "pontos de ouro", que são determinados pela taxa de equilíbrio mais os custos de transporte do metal precioso de um país a outro (Ricardo, 1811: 19).

$\mathrm{Na}$ verdade, até a noção de que o valor do papel-moeda inconversível depende da quantidade em circulação - base da crítica de Ricardo ao Banco da Inglaterra em 1808-1811 — é a mesma de Smith, embora este último, ao contrário de Ricardo, realce a confiança como a relação entre essas duas variáveis. Como resultado da emissão monetária excessiva, num contexto de ausência de conversibilidade, a taxa de câmbio de mercado se coloca permanentemente acima da paridade, ao mesmo tempo em que o ouro passa a ser contado com um prêmio em relação à libra-papel (Ricardo, 1811: 21). Esta seria, então, a explicação para o que ocorrera na Inglaterra após a suspensão da conversibilidade da libra papel, em 1797.

A explicação bullionista - como no caso da fornecida por Ricardo - da elevação da taxa de câmbio, com a sua permanência num patamar acima do ponto superior do ouro, do prêmio do ouro em relação ao valor nominal correspondente do papel-moeda e da elevação do nível de preços, assentava-se, pois, em Smith, pois esse seria o resultado esperado de qualquer emissão que ultrapassasse os requerimentos da circulação, mensuradas através da quantidade de ouro ou prata que circulariam num regime de moeda-mercadoria. Está claro que, quaisquer que fossem as suas causas, também a valorização cambial seria esperada como conseqüência de déficits no balanço de pagamento.

Essas mesmas idéias monetárias foram sumarizadas de forma confusa no Capítulo XXVII dos Princípios de Economia Politica e Tributação, que se inicia com Ricardo (1817: 239) afirmando que:

"o ouro e a prata, como todas as outras mercadorias, somente têm valor na proporção da quantidade de trabalho necessário para a sua produção e sua colocação no mercado. O ouro é cerca de quinze vezes mais caro do que a prata, não porque exista uma grande demanda por ele ou porque a oferta de prata seja quinze vezes maior do que a de ouro, mas somente porque é necessário uma quantidade de trabalho quinze vezes maior para produzir uma dada quantidade daquele metal."

Segue-se, portanto, que "a quantidade de dinheiro que pode ser utilizada em um país depende do seu valor" (Ricardo, 1817: 239), de modo que "o dinheiro 
em circulação jamais pode ser tão abundante que se torne excessivo, pois, ao diminuir seu valor, na mesma proporção aumenta sua quantidade, e, ao aumentar seu valor, diminui sua quantidade", que, assim, é endogenamente determinada.

Depois de ter estabelecido essas idéias aparentemente anti-quantitativistas, Ricardo (1817: 239) declara que "embora o papel-moeda não tenha valor intrínseco, na medida em que se limita sua quantidade, seu valor de troca pode igualarse ao valor de uma moeda com a mesma denominação, ou de um lingote do mesmo metal que a moeda". Segue-se, pois, que "não é necessário que o papel-moeda seja resgatável em espécie para garantir seu valor; basta que a sua quantidade seja regulada de acordo com o valor do metal adotado como padrão monetário" (Ricardo, 1817: 240). Em tom de ponderação, afirma ainda Ricardo (1817: 241):

“A experiência, no entanto, mostra que sempre que um Estado ou um Banco tiveram poder ilimitado de emitir papel-moeda, abusaram desse poder: portanto, em todos os Estados é necessário que exista um freio e um controle sobre a emissão de papel-moeda, e nada parece mais adequado para esse propósito do que obrigar os emissores de papel-moeda a converter suas notas em ouro cunhado ou em lingotes".

\section{VANTAGENS COMPARATIVAS E O AJUSTAMENTO DO BALANÇO DE PAGAMENTOS NO PADRÃO-OURO}

A seção 6 deixou claro que, para Ricardo, a oferta de meios de circulação ajusta-se à demanda quando as notas bancárias são conversíveis em ouro, de forma que o mecanismo de mudança do nível de preços como conseqüência da variação da quantidade de moeda em circulação - , engrenagem necessária para que prevaleça o princípio das vantagens comparativas - somente operaria num contexto de papel-moeda inconversível. Seria, pois, somente num regime de moeda fiduciária que a saída (entrada) de metal precioso resultante de qualquer déficit (superávit) no balanço de pagamentos efetivamente resultaria na contração (expansão) da oferta de moeda em circulação, causando a queda (elevação) dos preços em moeda estrangeira, o que conduziria ao aumento (queda) das exportações e redução (aumento) das importações, equilibrando o balanço de pagamentos.

Em contraposição, num contexto de conversibilidade, o equilíbrio no mercado monetário se dá segundo o descrito por Adam Smith: qualquer excesso de oferta (demanda) de meios de circulação provoca uma elevação (queda) dos preços das mercadorias - inclusive dos lingotes de ouro e/ou prata —, levando à valorização (desvalorização) cambial e ao surgimento de um ágio (desconto) da mercadoria-dinheiro em relação ao papel-moeda de igual valor nominal. Seguese um processo de refluxo das notas bancárias, que são apresentadas nos bancos para serem convertidas em metal precioso, e de remessa de ouro e prata para o exterior, o que traz de volta a taxa de câmbio ao seu valor de paridade, faz desaparecer o ágio das moedas metálicas sobre as notas de mesma denominação e eli- 
mina o excesso de oferta (demanda) de meios de circulação. Como resultado, o ajustamento do balanço de pagamentos não se opera através da flutuação do nível de preços, mas, através do fluxo de metal do país deficitário para o superavitário, o que preserva o nível de preços, embora possa levar à contração (expansão) do nível de atividades econômicas.

Segundo o mecanismo clássico concebido por Adam Smith, quando as ordens de pagamento emitidas pelos importadores de determinado país em favor dos exportadores de outro país se compensavam, a taxa de mercado de câmbio coincide com o valor da paridade, definida pela relação de peso das moedas de ouro dos dois países em metal de dado grau de pureza. Quando as ordens de pagamento não eram compensadas, de forma que o valor dos créditos contra o país era maior do que os créditos a favor desse país, a taxa de câmbio de mercado se elevava acima de seu valor de paridade, ocorrendo o inverso quando o país exportava mais do que importava. É claro que essas flutuações seriam comuns no mercado de câmbio, de forma que uma cotação acima da paridade em um dia era freqüentemente compensada por uma cotação abaixo da paridade no dia seguinte. Contudo, um déficit mais persistente da balança comercial fazia com que a taxa de câmbio de mercado se afastasse sistematicamente do valor da paridade, de modo que, mais cedo ou mais tarde, a diferença entre o valor de mercado da moeda estrangeira e o valor da paridade se tornasse maior do que os custos de transporte da moeda do país devedor para o credor. Quando isso ocorria, tornava-se lucrativo enviar barras de ouro ou mesmo ouro amoedado do país devedor para o credor, ou seja, o primeiro "exportava [remetia] dinheiro [ouro]" para o segundo. ${ }^{7}$

Evidentemente, uma situação de desequilíbrio permanente num país produtor de ouro não representaria um problema, na medida em que o saldo negativo da balança comercial significaria um componente da demanda final desse produto. Contudo, para um país não-produtor desse metal, somente seria possível manter um déficit permanente na balança comercial se o país deficitário pudesse se endividar de forma crescente no exterior, o que não seria efetivamente problemático se, em razão do crescimento das exportações, a relação dívida externa/exportações se mantivesse constante. Contudo, caso essa relação atingisse um teto, além do qual os credores do resto do mundo não estivessem dispostos a financiar o déficit do balanço de pagamentos, o país seria obrigado a restringir o seu ritmo de crescimento de forma a manter a balança comercial equilibrada. Mais do que isso, o ritmo de crescimento de sua economia ficaria na dependência do crescimento econômico do(s) parceiro(s) comercial(is). Caso a demanda por produtos nacionais se mantivesse estacionária ou recuasse, a eliminação do déficit comercial obviamente requereria a queda da renda nacional. Em outras palavras, o ajuste do balanço de pagamentos num regime de moeda-mercadoria se daria pelas flutuações do nível de renda, em lugar das variações do nível de preços,

\footnotetext{
${ }^{7}$ Veja-se Smith (1983 [1776], livro 4, Cap. III, v. 1: 395).
} 
conforme seria de se esperar num regime de moeda fiduciária, onde prevaleceria a teoria quantitativa da moeda. ${ }^{8}$

Em suma, o paradoxo do princípio das vantagens comparativas de Ricardo reside no fato de que, na melhor das hipóteses, ele operaria num regime fiduciário, pois nesse caso todo déficit (superávit) na balança comercial causaria uma redução (aumento) da oferta de moeda, pois haveria sempre conversão de moeda doméstica (libras-papel, como no caso da Inglaterra durante o Período da Suspensão) em moeda internacional (ouro e prata) para remessa (recebimento) ao (do) exterior, o que reduziria (aumentaria) a quantidade de moeda em circulação, produzindo não apenas uma valorização (desvalorização) cambial, mas uma queda (elevação) do nível de preços, o que favorecerá as exportações (importações) e desestimulará as importações (exportações). No padrão-ouro, contudo, não poderia haver qualquer flutuação do nível de preços, pois este depende dos custos de produção das mercadorias em relação aos custos de produção do ouro, que não são afetados pelo desequilíbrio na balança de comércio.

\section{CONCLUSÕES}

Uma análise sistemática dos escritos de David Ricardo sobre comércio internacional e teoria monetária revela sérios problemas na sua formulação da teoria das vantagens comparativas. Primeiramente, tal como esboçado no Capítulo VII dos Princípios, fica claro que essa teoria pressupõe a troca direta de produtos vinho português por tecidos ingleses —, o que parece ser dificilmente conciliável com a realidade de persistentes desequilíbrios da balança comercial. Tampouco parece satisfatória a explicação ricardiana do fenômeno, que somente ocorreria em situações de transição provocadas por mudanças tecnológicas, em que dada estrutura de preços relativos fosse alterada, com a inversão da ordem das vantagens comparativas. De resto, o processo seria marcado pela mudança das pautas de exportação/importação e pela redução drástica, ainda que temporária, do fluxo de comércio, o que contraria frontalmente a realidade do comércio internacional, caracterizada por desequilíbrios duradouros na balança comercial e pela persistência tanto das pautas como dos fluxos de comércio. Mas o maior problema reside na não aplicabilidade do princípio das vantagens comparativas num regime de moeda-mercadoria de aceitação universal, como no caso do padrãoouro. Num contexto desse tipo, o possuidor de dinheiro pode comprar o que quiser onde quiser, sendo, portanto, de se esperar que compre nos países onde os preços em ouro sejam mais baixos, sem qualquer consideração sobre os preços relativos. Tanto assim que um exame cuidadoso do exemplo do comércio entre

\footnotetext{
${ }^{8}$ Além disso, a entrada (saída) de ouro afetaria a capacidade dos bancos de conceder financiamentos, alterando a disponibilidade de crédito e a taxa de juros, o que acarretaria variações no nível de atividade da economia.
} 
Portugal e Inglaterra no Cap. VII dos Princípios de Ricardo, é capaz de revelar a existência de perdas monetárias, perdas que seriam evitadas caso os produtos comercializados fossem comprados no país onde são mais baratos em termos absolutos.

Contudo, poder-se-ia argumentar sobre os desequilíbrios na balança comercial resultantes de uma situação como essa na queda do nível de preços no país com balança deficitária e na elevação dos preços no país com balança superavitária, o que levaria, mais cedo ou mais tarde, ao equilíbrio da balança comercial, quando os dois países estivessem exportando reciprocamente os produtos em que tivessem vantagens relativas. Essa "segunda via" da teoria das vantagens comparativas, contudo, entra em choque com a teoria monetária do próprio Ricardo, que admitia que, numa situação de plena conversibilidade das notas bancárias em ouro - considerado como a moeda universal - não haveria espaço para a teoria quantitativa da moeda, que vincula as variações do nível de preços ao resultado do balanço de pagamentos via mudanças da quantidade de moeda em circulação. Ao endossar a "lei do refluxo" de Adam Smith, Ricardo aceita a noção de que o nível de preços é determinado pelos custos de produção do ouro em relação aos custos de produção das outras mercadorias, de forma que a quantidade de moeda em circulação se ajusta automaticamente à quantidade demandada. Em termos de balanço de pagamentos, isso significa que não são as flutuações no nível de preços, mas as flutuações no nível de renda que promovem o balanço entre oferta e demanda por divisas no longo prazo. Em suma, a "segunda via" da teoria das vantagens comparativas somente funcionaria, na melhor das hipóteses, num regime de moeda fiduciária, deixando de operar em qualquer sistema baseado em moeda-mercadoria, como no caso do padrão-ouro.

\section{REFERÊNCIAS BIBLIOGRÁFICAS}

ANGELL, J. W. (1925) The Theory of International Prices. New York: Kelley, 1965.

BHAGWATI, J. N. (ed.) (1969) International Trade. Selected Readings. Baltimore, Penguin Books.

BHAGWATI, J. N.; SRINIVASAN, T. N. (1984) Lectures in International Trade, Cambridge: MIT Press.

BRANDER, J.; SPENCER, B. (1985) Export subsidies and market share rivalry. Journal Of International Economics, 18(1/2): 83-100.

CANAN, E. (ed.) (1919) The Paper Pound of 1797-1821. New York: M. Kelley, 1969.

CARBAUCH, R. J. (2002) Economia Internacional. São Paulo: Pioneira Thompson Learning, 2004.

CAVES, R. E.; H. G. JOHNSON (eds.) (1968) Readings in International Economic. London: Allen and Unwin.

CHIPMAN, J. S. (1965a) A survey of the theory of international trade: Part 1, The classical theory. Econometrica, vol. 33(3): 477-519, Jul.

CHIPMAN, J. S. (1965b) A survey of the theory of international trade: Part 2, The neo-classical theory. Econometrica, vol. 33(4): 685-760, Oct.

CHIPMAN, J. S. (1966) A survey of the theory of international trade: Part 3. The modern theory. Econometrica, vol. 34(1): 18-76, Jan.

DOBBS, A. (1729) An Essay on the Trade and Improvement of Ireland. Dublin: Rhames.

DORNBUSCH, R.; FISCHER, S.; SAMULESON, P. A. (1977) Comparative advantage, trade, and 
payments in a Ricardian model with a continuum of goods. American Economic Review, 67, Dez.

EATON, J.; GROSSMAN, G. (1986) Optimal trade and industrial policy under oligopoly. Quarterly Journal of Economics, 101(2): 283-406.

EVANS, H. D. (1989) Comparative Advantage and Growth. New York, St. Martin's Press.

FINDLAY, R. (1974) Relative prices, growth and trade in a simple Ricardian system. Economica, 41(Fev): 1-13.

Comparative advantage, in J. EATWELL; M. MILGATE, M.; O. NEWMAN (eds.) (1987)

The New Palgrave: a Dictionary of Economics, vol. 1. London: Macmillan, pp. 514-517.

FFRENCH-DAVIS, R. (1978) Economia Internacional. Ciudad del México: Fondo de Cultura Económica, 1985.

GOMES, L. (1987) Foreign Trade and the National Economy: Mercantilism and Classical Perspectives. New York: St. Martin's Press.

GONÇALVES, R.; BAUMANN, R.; CANUTO, O; PRADO, L. C. D. (1998) A Nova Economia Internacional. Rio de Janeiro: Campus.

GONER, E. C. K. (ed.) (1923) Economics Essays by David Ricardo. London: Bell and Sons.

GROSSMAN, G.; HELPMAN, E. (1991) Innovation and Growth in the Global Economy. Cambridge: MIT Press.

GROSSMAN, G.; HORN, (1988) H. Infant industry protection reconsidered: the case of international barriers to entry. Quarterly Journal of Economics, 103(4): 767-787.

HOLANDER, J. H. (ed.) (1923) Minor Papers on the Currency Question, 1809-1823 by David Ricardo. Baltimore: Hopkings Press.

HUTCHESON, F. (1753) Introduction to Moral Philosophy. Glasgow: R. \& A. Foulis.

HUME, D. (1747) Essays Moral, Political, and Literary. London: Lubbock, 1894.

IRWIN, D. A. (1996) Against the Tide. Princeton: Princeton University Press.

JANSSEN, T. (1713) General Maxims in Trade. London: S. Bucley.

KRUGMAN, P. (1984) Import protection as export protection. In: KIERKOWSKY, H. (ed.), Monopolistic Competition and International Trade. Oxford: Oxford University Press, pp. 180-193. (1986) Strategic Trade Policy and the New International Economics. Cambridge: MIT Press.

MAINWARING, L. (1979b) A neo-Ricardian analysis of international trade, Australian Economic Papers, 1973. Reeditado em I. STEEDMAN, pp. 111-122.

MANESCHI, A. (1992) Ricardo's international trade theory: beyond the comparative cost example, Cambridge Journal of Economics, 16 (Dez.): 421-437.

METCALFE, J. S.; I. STEEDMAN. (1972) Reswitching, primary inputs and the Heckscher-Ohlin-Samuelson theory of trade, Journal of International Economics, Mar. Reeditado em I. STEEDMAN, 1979a, pp. 38-46.

METCALFE, J. S.; I. STEEDMAN. (1973) Heterogeneous capital, and the Heckscher-Ohlin-Samuelson theory of trade. In J. M. PARKIN, J. (ed.) Essays in Modern Economics, London, Longman. Reeditado em I. STEEDMAN, 1979a, pp. 64-76.

METCALFE, J. S.; I. STEEDMAN. (1974) A note on the gain from trade, Economic Record, 50: 581-595. Reeditado em I. STEEDMAN, 1979, pp. 99-109.

RICARDO, D. (1817) Princípios de Economia Política e Tributação. Tradução de P. H. R. Sandroni. São Paulo: Victor Civita, 1982.

RICARDO, D. (1811) High Price of Bullion. Reeditado em RICARDO, D. Economic Essays. London: G. Bell and Sons, 1923, pp. 3-60.

RICARDO, D. (1811) Reply to Mr.Bonsanquet's Practical Observations on the Report of the Bullion Comittee, 1811. Reeditado em RICARDO, D. Economic Essays. London: G. Bell and Sons, 1923, pp. 61-102.

RICARDO, D. (1816) Proposals for and Economic and Secure Currency. Reeditado em RICARDO, D. Economic Essays. London: G. Bell and Sons, 1923, pp. 103-176.

SAMUELSON, P. A. (2001) A Ricardo-Sraffa paradigm comparing gains from trade in inputs and finished goods. Journal of Economic Literature, 39(Dec.): 1204-1214. 
SHAIKH, A. (1979a) Foreign trade and the law of value: Part I, Science and Society, 43(Aut.): 281302.

SHAIKH, A. (1979b) Foreign trade and the law of value: Part II, Science and Society, 44(Spr.): pp. 27-57.

SMITH, A. (1776) A Riqueza das Nações. São Paulo: Victor Civita, 1983.

STEEDMAN, I. (ed.) (1979a) Fundamental Issues in Trade Theory. New York: St. Martin's Press.

STEEDMAN, I. (1979b) Trade Amongst Growing Economies. Cambridge: Cambridge University Press.

STEUART, J. (1757) An Inquiry into the Principles of Political Economy. Edinburgh: Oliver \& Boyd, 1966.

TUCKER, J.(1758) Instructions for Travelers. Dublin: W. Watson.

VICKERS, D. (1959) Studies in the Theory of Money, 1692-1776. Philadelphia: Chilton Company.

VICKERS, D. (1975) Adam Smith and the Status of Money, in SKINNER, A. S.; WILSON, T. Essays on Adam Smith. Oxford: Clarendon Press, pp. 482-503.

VINER, J. (1937) Studies in the Theory of International Trade. New York: Kelley, 1965.

WILlIAMSON, J. (1993) Economia Aberta e a Economia Mundial. Rio de Janeiro: Campus, 1998.

WOOD W. (1718) A Survey of Trade. London: W. Wilkins.

YARRANTON, A. (1677) England's Improvement by Sea and Land. London: Everingham. 